\title{
A Evolução do Mercado de Trabalho no Estado do Ceará na Indústria de Transformação no Setor Têxtil de 2006 e 2014
}

\author{
Ane Caroline Rodrigues
}

(Mestranda em Desenvolvimento Regional Sustentável pela Universidade Federal do Cariri - UFCA)

Cícera Vivane Barros

(Graduada em Economia pela Universidade Regional do Cariri - URCA; Bolsista de IC do Programa PIBIC-URCA)

Francisco do O’ de Lima Junior

(Professor Associado do Departamento de Economia URCA; Professor do Programa de Pós-graduação em Planejamento e Dinâmicas Territoriais do Semiárido - PLANDITES)

\begin{abstract}
Resumo:
O presente artigo tem como objetivo analisar, em 2006 e 2014, precisamente antes do primeiro mandato do governo Cid Gomes (2006) e ao término do seu segundo mandato (2014), as características da indústria de transformação instaladas no Ceará, especificamente, o setor têxtil formal e, notadamente, traçar o perfil sociodemográfico e socioeconômico dos empregados em tal atividade, procurando verificar se houve avanços ou retrocessos tanto neste setor, como no mercado de trabalho cearense. Para tanto, foram utilizados dados da Relação Anual de Informações Sociais (RAIS), do Ministério do Trabalho e Emprego (MTE). Em termos teóricos foi feita uma breve descrição sobre o processo de industrialização cearense, citando a criação do Fundo de Desenvolvimento Industrial (FDI). Os principais resultados mostram no intervalo em estudo, aumento na quantidade absoluta e relativa de estabelecimentos industriais instalados no Ceará, notadamente no setor da construção civil. No que concerne ao número de trabalhadores, houve criação de vagas, entre 2006 e 2014. Já o setor têxtil industrial, foco de análise desse estudo, mostrou-se com avanços em termos de ocupação nos anos em análise. Quanto ao perfil dos empregados na indústria têxtil formal cearense, os dados revelam que estes são expressivamente do sexo feminino, têm entre 30 a 39 anos (idade considerada ativa), possuem o ensino médio completo até o superior incompleto, permanecem por um ano a menos de três no mesmo emprego e auferem de 1 a 2 salários mínimos. Ademais, embora o nível educacional tenha melhorado expressivamente, o salário permanece baixo, e com espaço bastante equilibrado para a mão de obra de ambos os sexos, embora o feminino esteja na frente (em termos percentuais). Assim, empregos no setor têxtil foram criados, porém precários, e determinados pelos incentivos fiscais adotadas pelo governo do Estado, mostrando que ainda se há muito para com o que se avançar.
\end{abstract}

Palavras-Chaves: Ceará; Indústria têxtil; Mercado de trabalho formal.

\begin{abstract}
:
This article aims to analyze, in 2006 and 2014, more precisely before the first government mandate Cid Gomes (2006) and at the end of his second term (2014), processing industry characteristics installed in Ceará, but specifically, the formal textile sector and, in particular, to trace the socio-demographic and socioeconomic profile of employees in such activity, looking whether there has been progress or setbacks both in this sector, as in Ceará labor market. For this, we used data from the Annual Social Information (RAIS) of the Ministry of Labor and Employment (MTE). In theory it was made a brief description of the Ceará industrialization process, citing the creation of the Industrial Development Fund (IDF). The main results show the interval under study, an increase in absolute and relative number of industrial establishments located in Ceará, especially in the construction sector. Regarding the number of employees, there was job creation between 2006 and 2014. The industrial textile sector, the focus of analysis of this study, it was shown with advances in
\end{abstract}


terms of occupation in the years under review. Regarding the profile of employees in the formal textile industry Cearense, the data show that these are mostly female are between 30 to 39 years (considered active age), have completed high school to incomplete higher, remain for one year to less than three in the same job and earn 1 to 2 minimum wages. In addition, while the educational level has improved significantly, the salary remains low and well balanced for the manpower of both sexes space, although the female is in front (in percentage terms). Thus, jobs in the textile sector have been created, however precarious, and certain tax incentives adopted by the state government, showing that even if there is a lot to with that move.

Keywords: Ceará; Textile industry; Formal labor market.

\section{1) INTRODUÇÃO}

A compreensão acerca dos fatores que influenciaram a dinâmica do mercado de trabalho na economia do Ceará, especialmente na indústria de transformação, perpassa pela influência dos reflexos obtidos com o processo de industrialização cearense (iniciado desde a década de 1960) sobre este (BARBOSA et al., 2012).

Quando as políticas macroeconômicas foram implementadas no Brasil (principalmente a partir dos anos 1990), a problemática do emprego aumentou, devido às diversas oscilações na produção e consumo que o sistema econômico sofreu (BARBOSA et al., 2012). Como aponta Dedecca (2005), aqueles que aspiravam ao primeiro emprego na década de 1990, se depararam com grandes dificuldades de inserção no mercado de trabalho, sendo estas, decorrentes das exigências de qualificação e experiência que se tornavam cada vez maiores.

Quanto ao Ceará, na década de 1990, o mesmo conduziu uma política industrial baseada na concessão de incentivos fiscais, para atração de investimentos e fomento à industrialização. Isto teve reflexos no desempenho econômico, uma vez que o PIB (Produto Interno Bruto) cresceu nesse período a taxas maiores que o nacional, destacando-se o aumento da participação do setor industrial, em especial na construção civil e indústria de transformação (IPECE, 2009). Ressalta-se que no ano de 2009 o Ceará apresentou a segunda maior geração de emprego do Nordeste sendo superado apenas pelos Estados de Pernambuco e Bahia (BNB, 2010).

Cabe destacar, que o contexto macroeconômico da década de 1950, coloca o Ceará dentro da iminente obrigação de se deixar conduzir pela globalização da lógica de reprodução do capital (LIMA JÚNIOR, 2014). Nesse viés, programas de incentivos como o Fundo Industrial de desenvolvimento (FDI) e o órgão estadual a Superintendência de 
Desenvolvimento do Nordeste (SUDENE), foram criados com o objetivo de impulsionar a industrialização cearense e descentralizá-la da Região Metropolitana de Fortaleza- RMF (ARAÚJO 2007; QUEIROZ E SILVA, 2010).

Nesse sentido, empenhados em fortalecer a economia nordestina dentro da lógica do capital, é que alguns governos criaram uma gama de incentivos voltados à pauta industrial. Assim, desde o governo de Virgilio Távora passando pelo mandato de Tasso Geiressati até o governo de Cid Gomes, é que políticas estaduais, creditícias e fiscais foram criadas a fim de dinamizar e diversificar um setor primordial, no entanto até então insipiente nessa economia: o da industrialização (ARAÚJO, 2007).

A atividade industrial para o Ceará é de extrema importância, isso porque, além de produzir bens de consumo não duráveis como alimentos e bebidas, têxtil, vestuário, couro e calçados, gera empregos, dado que tais atividades são intensivas em mão de obra (DINIZ, 2004).

Sabe-se que nos anos do Governo Cid Gomes (2006 a 2014), muitos foram os investimentos na construção civil, porém a indústria (especialmente a de transformação, a qual é destaque deste estudo), também teve seu espaço priorizado. Esta, por sua vez, cresceu, e gerando empregos, favoreceu ainda mais o mercado de trabalho neste setor. Dessa maneira, os investimentos e o apoio de infraestrutura às empresas que desejassem ampliar, modernizar ou investir em novas instalações, possibilitou o dinamismo industrial cearense (BARBOSA et al., 2012; IPECE, 2009).

Assim sendo, este trabalho procura responder a seguinte questão: como tem evoluído a indústria de transformação, especificamente o setor têxtil nos anos de 2006 e 2014? E quem são os trabalhadores ocupados em tal setor de atividade econômica?

Portanto, pretende-se analisar as características da indústria de transformação no setor têxtil, bem como o mercado de trabalho do Estado do Ceará neste setor de 2006 e 2014 (Governo Cid Gomes). Para tanto, irá se contextualizar estudos sobre o processo de industrialização no Estado do Ceará. Mostrar a evolução do número de trabalhadores no setor têxtil nos anos de 2006 e 2014. E, traçar as características da indústria e o perfil socioeconômico e sociodemográfico dos trabalhadores inseridos no setor têxtil cearense.

Posto isto, trata-se de uma pesquisa essencialmente exploratória, sustentada a partir de dados secundários da Relação Anual de Informações Sociais (RAIS) e Ministério do Trabalho e Emprego (MTE), tomando como 
material de apoio artigos, teses e publicações variadas relacionadas ao estudo em foco. Dessa maneira, os dados coletados referem-se à dinâmica do mercado de trabalho no Ceará nos anos de 2006 e 2014, correspondentes a antes e durante os mandatos de Cid Gomes.

A hipótese deste estudo é que o setor têxtil da indústria de transformação cearense tem se consolidado cada vez mais, movimentando a economia cearense e favorecendo ao mercado de trabalho.

Para alcançar os objetivos propostos, o artigo encontra-se estruturado da seguinte forma: além dessa introdução, a segunda seção aborda o processo de industrialização cearense. A terceira analisa a evolução do mercado de trabalho no setor têxtil da indústria de transformação. Em seguida, analisamse as características da indústria cearense e o perfil sociodemográfico e socioeconômico dos empregados formais na indústria têxtil cearense. Por último, apresentam-se as conclusões do estudo.

\section{2) O PROCESSO DE INDUSTRIALIZAÇÃO CEARENSE}

A industrialização constitui o caminho pelo qual se torna possível alcançar as bases para a consolidação do desenvolvimento (MORAIS, 2006).

A industrialização do Ceará foi um processo que se deu de forma compassada e desigual, consoante à custa de políticas estaduais, reflexo da economia brasileira e internacional à época, iniciando seus primeiros traços lá pelo início da década de 1960 e final de 1980, onde o Governo do Estado do Ceará por meio de políticas de industrialização, promove a interiorização das indústrias para este estado, reorganizando o espaço geográfico para a “produção e reprodução" (ARAÚJO 2007).

Cabe destacar, que como resultado da organização territorial do espaço cearense, as diversas heranças seculares pelo qual foi o mesmo submetido. Que, como se sabe, teve à priori, uma economia pautada basicamente no binômio pecuário-algodoeiro, cujo modelo é o que cria as bases para que a capital cearense pudesse, dentro do período colonial, se tornar centro urbano (fato que se tornou possível por causa da geração e centralização dos excedentes produzidos naquelas duas atividades sertanejas já citadas, a lembrar de que foi o algodão o produto que mais dinamizou e transformou as estruturas e as formas de reprodução do capital desta economia) (MACEDO, LIMA JÚNIOR e MORAIS, 2012).

Este produto promoveu o florescimento de importantes núcleos urbanos no sertão. Como, por exemplo, Iguatu, Quixadá, Quixeramobim e, 
principalmente, Icó, além do Crato na região do Cariri (no sul do estado), tornando-os progressivamente tributários da capital, em especial a partir da consolidação das ferrovias no século XIX que organizariam o espaço cearense de forma muito mais definida e duradoura do que as antigas rotas do gado. Tal processo preparou lentamente as condições materiais para a incorporação do espaço cearense à lógica de acumulação que emergiria com a industrialização brasileira na segunda metade do século XX (MACEDO, LIMA JÚNIOR e MORAIS, 2012).

No período que compreende o Governo Tasso Gereissati, se ver uma espécie de "configuração [da] nova organização espacial [que] ocorre devido aos interesses do capital que promove a industrialização". É nesse governo que inicia a adoção de políticas de desenvolvimento voltadas para o Estado e Nordeste. Sendo parte dessas políticas, a de incentivos fiscais (que serviu de atração para o grande polo industrial da Grendene para o Ceará) (ARAÚJO 2007).

Tasso Jereissati, em seu primeiro mandato, tinha a pretensão de tornar forte a indústria interna, a ponto de gerar "externalidades positivas" para a economia cearense no quadro tanto regional como nacional. Isso se daria por meio da substancial e vultosa injeção de investimentos externos levantados pelo Fundo de Desenvolvimento Industrial do Ceará (FDI), um programa voltado para atração industrial. Sem embargo, é preciso levar em consideração os investimentos também advindos de órgãos regionais e nacionais, como o Fundo de Investimento do Nordeste (FINOR) (criado no II PND para corrigir as possíveis falhas do sistema de incentivos); o Fundo Constitucional de Financiamento do Nordeste (FNE) e o Banco Nacional de Desenvolvimento Econômico e Social (BNDS) (ALMEIDA, 2001).

Destarte, o governo de Vírgilio Távora se inicia com a adoção de políticas de desenvolvimento voltadas para o Estado e Nordeste. À saber, faz parte dessas políticas: a de incentivos fiscais (que inclusive, serviu de atração para o grande polo industrial da Grendene para o Ceará). Com base nisso, tomou-se medidas de atração de recursos com a finalidade de transformar o Estado em III Polo Industrial do Nordeste, a fim de promover o fortalecimento do parque industrial, implantação e consolidação dos distritos industriais. Tais recursos foram provenientes do Fundo de Desenvolvimento Industrial do Ceará (FDI), da Superintendência de Desenvolvimento do Nordeste (SUDENE), Banco do Brasil (BB), Banco Nacional de Desenvolvimento Social (BNDS) e Banco do Nordeste (BNB) e etc. Todas essas ações fazem parte do Plano de Metas Governamental (PLAMEG), 
primeiro plano estadual de governo implantado por Távora, que se estendeu de 1963 até 1966, e que foi levado à cabo também em outros mandatos, porém com alguns detalhes distintos deste (ARAÚJO, 2007).

Vale ressaltar, que apesar de os recursos provenientes daquele primeiro terem sido mais eficiente do que os outros, todo o empenho foi insignificante, uma vez que a meta não foi atingida e os investimentos se concentraram apenas no setor têxtil, alimentar e calçadista (ARAÚJO 2007).

O PLAMEG tinha como principais objetivos a construção de distritos industriais, de infraestrutura básica, Banco estadual e eletrificação. Faz-se importante destacar que até o ano de 1962, no Ceará, não havia energia elétrica, o que dificultava o desenvolvimento da região e principalmente impossibilitava o processo de industrialização (GONÇALVES, 2006).

Acerca do FDI, sabe-se que foi criado em 1979, cujo papel principal era o de funcionar como um programa de incentivos fiscais e financeiros para setores considerados dinâmicos, com o viés de integrar a economia do Ceará na pauta inter e intra do Estado (PONTES, VIANA E HOLANDA, 2006).

Deve-se frisar que a criação do Fundo era apenas uma das medidas que pretendiam transformar o Ceará no terceiro pólo industrial do Nordeste. Entre outras intervenções havia a instalação de uma indústria siderúrgica, uma refinaria de petróleo, a modernização do parque têxtil do Ceará etc. Previa-se, ainda, estreita cooperação entre os governos estadual e federal (PONTES, VIANA E HOLANDA, 2006, p. 6).

Portanto, esse interesse no plano regional, argumenta Carvalho (2001), vai além da representação de um objetivo implícito de desconcentração industrial, surge com a concepção dos Polos ou Complexos Industriais como possibilidade de angariar maiores externalidades e efeitos multiplicadores para a economia regional. Somado a este propósito, a reformulação de um sistema de incentivos fiscais voltados ao desenvolvimento dos complexos industriais, que surgiu em 1974, o FINOR.

Como se pode observar até aqui, o processo de industrialização é interiorizado no Ceará a partir das políticas regionais e de incentivos fiscais, cambiais e creditícios para o Nordeste. Ademais, vale lembrar, que a criação da SUDENE em 1959, motivada pelo desejo de descentralizar e estimular a indústria nesse Estado, alcançou seu auge entre os anos de 1961 e 1967, quando a economia do Nordeste chegou a superar a economia nacional em matéria de crescimento (DINIZ, 2009). 
Cabendo destacar, que a SUDENE foi a primeira experiência de Planejamento Regional no Brasil, e tinha como objetivo corrigir as desigualdades espaciais que se ampliavam pelo território à medida que avançava o processo de constituição do mercado interno alavancado pela industrialização do país (CARVALHO, 1979).

A SUDENE foi por um bom tempo, considerada a "tábua de salvação" do Nordeste. Contudo, não conseguiu cumprir com eficiência suas metas, motivo de descontentamento e crítica entre os que afirmaram que ela apenas (re) concentrou a acumulação de capital entre os centros mais dinâmicos considerados pela lógica global do capitalismo, marginalizando a periferia, principal impasse para os centros urbanos industrializados. Por outro lado, tem os que acreditam o contrário (CARVALHO, 1979).

Dessa maneira, para orientação da análise do processo de industrialização, faz-se importante destacar que, o mesmo foi considerado como: fase em que a indústria é implantada de forma insipiente pelo beneficiamento de produtos primários (do século XIX até os anos de 1950); etapa em que há diversificação e modernização produtiva, que acontece sob a orientação planejada do governo (entre os anos de 1980 a meados dos anos de 1980) e; fase em que se tem a reestruturação produtiva da indústria sob a renovação político-econômica de acordo com a matriz político-econômica de regulamentação capitalista e inserção competitiva (a partir da década de 1980 em diante) (LIMA JUNIOR, 2014).

Entretanto, embora diversas medidas tenham sido implementadas para desenvolver a industrialização no Estado do Ceará, durante a chamada "Era Tasso/Jereissati", e nos governos Ciro Gomes e Cid Gomes, em busca da consolidação da industrialização "modernizadora":

[...] as alterações não se fazem com a implantação de modernas técnicas e/ou inovações, a exemplo da cibernética, robótica e outros, ou mesmo com alterações nas formas de produção, senão pela integração de novas e velhas formas de acumulação do capital, na busca da ampliação das taxas de lucros (ARAÚJO, 2007, p. 105).

Em suma, embora tenham havidos diversos investimentos na construção civil (construção de universidades, creches e escolas, minha casa minha vida, entre outros) no Governo Cid Gomes, a política de industrialização ainda é pautada em incentivos fiscais (ROCHA, 2002). 


\section{3) EVOLUÇÃO DO MERCADO DE TRABALHO NO SETOR TÊXTIL DA INDÚSTRIA DE TRANSFORMAÇÃO}

Essa seção analisa a evolução do setor têxtil de atividade e o comportamento do mercado formal de trabalho no Estado do Ceará, antes do governo Cid Gomes (2006) e após o término do seu segundo mandato (2014), procurando examinar se houve avanços ou não em tal setor, durante o período que compreende os seus dois mandatos consecutivos.

\section{1) Características da Indústria Cearense}

A Tabela 1 traz a quantidade de estabelecimentos instalados no Ceará, mostrando que em 2006, o estado contava com 59.993 mil unidades. Desse total, havia uma concentração em atividades comerciais $(46,44 \%)$, seguida pelos serviços $(33,84 \%)$, indústria $(13,36 \%)$, construção civil $(4,81 \%)$ e agropecuária com apenas $1,56 \%$.

Nesse cenário, embora a indústria não se revelasse como a principal atividade econômica do Ceará (13,36\%), o PIB industrial cearense representa cerca de 17,2 bilhões de reais, sendo, portanto, o terceiro maior PIB de todo o Nordeste (CONFEDERAÇÃO NACIONAL DA INDÚSTRIA - CNI, 2014).

Tabela 1: Número de estabelecimentos segundo grande setor de atividade econômica - Ceará - 2006/2014

\begin{tabular}{cccccc}
\hline \multirow{2}{*}{ Setor de atividade } & \multicolumn{2}{c}{2006} & \multicolumn{2}{c}{$\mathbf{2 0 1 4}$} & Variação \\
& Abs. & $(\boldsymbol{\%})$ & Abs. & $(\boldsymbol{\%})$ & $\mathbf{( \% )}$ \\
$\mathbf{2 0 0 6 / 2 0 1 4}$ \\
\hline Indústria & 8.016 & 13,36 & 12.064 & 12,27 & 50,50 \\
Construção Civil & 2.885 & 4,81 & 6.718 & 6,83 & 132,86 \\
Comércio & 27.860 & 46,44 & 44.685 & 45,43 & 60,39 \\
Serviços & 20.299 & 33,84 & 33.489 & 34,05 & 64,98 \\
Agropecuária & 933 & 1,56 & 1.401 & 1,42 & 50,16 \\
Total & $\mathbf{5 9 . 9 9 3}$ & $\mathbf{1 0 0 , 0 0}$ & $\mathbf{9 8 . 3 5 7}$ & $\mathbf{1 0 0 , 0 0}$ & $\mathbf{6 3 , 9 5}$ \\
\hline
\end{tabular}

Fonte: Elaborado pelos autores a partir da RAIS/MTE.

No tocante ao ano de 2014, houve uma variação de 63,95\% (entre os anos estudados) ao atingir 98.357 unidades. Em nível setorial, o comércio permanece predominando com $44.685(45,43 \%)$ estabelecimentos, seguido pelos serviços $(34,05 \%)$, indústria $(12,27 \%)$, construção civil $(6,83 \%)$ e, por 
último, a agropecuária (1,42\%). Cabe destacar, que de acordo com Bezerra e Barbosa (2010), todos os setores apresentam crescimento, sobretudo no setor de construção civil. Isto devido a construção de vários empreendimentos (por assim dizer). Tais como: construção de prédios públicos: hospitais, ginásios poliesportivos, escolas, programas de habitação, entre outros.

No que concerne ao número de estabelecimentos por grandes setores (Tabela 2), no ano de 2006, os destaques são para Indústria Têxtil (2.502 estabelecimentos), seguido por Alimentos e Bebidas (1.762), Madeira e Mobiliário (598), Indústria Metalúrgica (527) e Papel e Gráfica (516). Em termos percentuais, a indústria têxtil (foco deste estudo) evidencia uma concentração de estabelecimentos com variação de $31,21 \%$ neste setor de atividade. $\mathrm{O}$ que mostra que este setor vem crescendo ao longo dos anos. De acordo com Bezerra e Barbosa (2010), a Indústria de Transformação, vem se mostrando cada vez mais ativa para o aquecimento da economia cearense, com destaque para os setores têxtil e calçadista. Porém, outros setores vêm se destacando, como: Produtos Alimentícios, Couro e Peles e Vestuário. Fazendo com que a indústria cearense se destaque em termos de crescimento, quando comparada ao Nordeste e ao Brasil.

Tabela 2: Número de estabelecimentos segundo grandes setores da indústria Ceará - 2006/2014

\begin{tabular}{cccccc}
\hline Setor de indústria & \multicolumn{2}{c}{$\mathbf{2 0 0 6}$} & \multicolumn{2014}{c}{} & $\begin{array}{c}\text { Variação } \\
(\mathbf{\%})\end{array}$ \\
& Abs. & $\mathbf{( \% )}$ & Abs. & $\mathbf{( \% )}$ & $\mathbf{2 0 0 6 / 2 0 1 4}$ \\
\hline Extrativa Mineral & 132 & 1,65 & 195 & 1,62 & 47,73 \\
Prod. Mineral Não Metálico & 508 & 6,34 & 838 & 6,95 & 64,96 \\
Indústria Metalúrgica & 527 & 6,57 & 1.009 & 8,36 & 91,46 \\
Indústria Mecânica & 160 & 2,00 & 425 & 3,52 & 165,63 \\
Elétrico e Comunicação & 52 & 0,65 & 104 & 0,86 & 100,00 \\
Material de Transporte & 91 & 1,14 & 149 & 1,24 & 63,74 \\
Madeira e Mobiliário & 598 & 7,46 & 808 & 6,70 & 35,12 \\
Papel e Gráfica & 516 & 6,44 & 803 & 6,66 & 55,62 \\
Borracha, Fumo, Couros & 348 & 4,34 & 544 & 4,51 & 56,32 \\
Indústria Química & 441 & 5,50 & 602 & 4,99 & 36,51 \\
Indústria Têxtil & 2.502 & 31,21 & 3.641 & 30,18 & 45,52 \\
Indústria Calçados & 261 & 3,26 & 371 & 3,08 & 42,15 \\
Alimentos e Bebidas & 1.762 & 21,98 & 2.325 & 19,27 & 31,95 \\
Serviço Utilidade Pública & 118 & 1,47 & 250 & 2,07 & 111,86 \\
Total & $\mathbf{8 . 0 1 6}$ & $\mathbf{1 0 0 , 0 0}$ & $\mathbf{1 2 . 0 6 4}$ & $\mathbf{1 0 0 , 0 0}$ & $\mathbf{5 0 , 5 0}$ \\
\hline
\end{tabular}

Fonte: Elaborado pelos autores a partir da RAIS/MTE. 
No ano de 2014, a Indústria Têxtil salta para 3.641 estabelecimentos, com variação menor que no primeiro ano $(31,21 \%)$ estudado $(30,18 \%)$. O setor de alimentos e Bebidas continua sendo o segundo com o maior número de estabelecimentos (2.325), com variação de 19,27\%. Em seguida, vêm os setores de Indústria Metalúrgica (1.009), Produto Mineral Não Metálico (838), Madeira e Mobiliário (808) e Papel de Gráfica (803). O que se observa é que todos aumentaram de forma significativa. Alguns com variações menores que no ano de 2006, outros com variações percentuais maiores, como é caso da Indústria Metalúrgica (de 6,57\% (2006) para 8,36\%) e Produto Mineral Não Metálico (de 6,34\% para 6,95\%). Mas, todos com aumento de estabelecimentos e com um destaque para a Indústria têxtil que vem criando cada vez mais estabelecimentos no Estado do Ceará.

Isso se deve as políticas implantadas no Ceará de atração de indústrias. Assim, com o melhoramento na condução da política econômica cearense, nota-se um destaque para os setores têxtil, calçadista e alimentício (QUEIROZ E MOREIRA, 2008). Sendo o primeiro um dos que mais se observa com um avanço bastante expressivo ao longo dos anos (IPECE, 2012c).

Considerando a evolução absoluta dos trabalhadores formais na indústria têxtil (Tabela 3), dentre os anos de 2006 a 2014 (primeiro e segundo mandato do Governo Cid Gomes), nota-se que entre os anos 2006 (52.598) e 2010 (71.006), houve um aumento do número de trabalhadores, com variações bastante expressivas (31,23\%). Cabendo destacar os anos 2008 (62.706) e 2010 (71.006), onde se observou um salto no número de trabalhadores, evidenciando o que Silva Filho e Queiroz (2009) colocam que a elevação no número de empregados nos estabelecimentos industriais cearenses vem avançando, ligado diretamente à criação de um fundo de atração de indústrias (principalmente, no ramo de transformação, as quais são intensivas em mão de obra), o Fundo de Desenvolvimento Industrial (FDI).

Nos anos seguintes (2011 a 2014), observa-se uma leve queda comparada ao ano anterior (cai de 71.006 (2010) para 70.178 (2014)), com oscilações e variações ora positivas, ora negativas. Mostrando que nos anos estudados, houve sim, quedas no número de trabalhadores, porém quando comparados os anos de 2006 e 2014, nota-se um avanço significativo de 52.598 trabalhadores para 70.178 trabalhadores. Representando assim, um aumento expressivo de trabalhadores na indústria têxtil de atividade, evidenciando sua consolidação no mercado e participação ativa na economia cearense. 
A evolução do mercado de trabalho no Ceará se deve as políticas de ajustes implantadas no estado, associada às isenções fiscais, a fim de atrair indústrias para o território cearense e gerar oportunidades de empregos (IPECE, 2012c).

Tabela 3: Evolução absoluta de trabalhadores formais na indústria têxtil cearense - 2006-2014

\begin{tabular}{ccc}
\hline Ano & Número de trabalhadores & Variação $(\boldsymbol{\%})$ \\
\hline 2006 & 52.598 & 0,00 \\
2007 & 58.046 & 10,36 \\
2008 & 62.706 & 8,03 \\
2009 & 65.969 & 5,20 \\
2010 & 71.006 & 7,64 \\
2011 & 69.299 & $-2,40$ \\
2012 & 70.719 & 2,05 \\
2013 & 71.133 & 0,59 \\
2014 & 70.178 & $-1,34$ \\
Total & $\mathbf{5 9 1 . 6 5 4}$ & $\mathbf{3 0 , 1 3}$ \\
\hline
\end{tabular}

Fonte: Elaborado pelos autores a partir da RAIS/MTE.

Considerando o número de trabalhadores formais (Tabela 4), nota-se que no ano de 2006, havia uma maior concentração de trabalhadores do ramo têxtil nas pequenas empresas (16.578 trabalhadores). Enquanto no ano de 2014, os trabalhadores concentravam-se em sua maioria nas grandes empresas. Cabe destacar, que os demais tamanhos de indústrias aumentam o número de trabalhadores empregados formalmente.

Tabela 4: Número de trabalhadores formais na indústria têxtil cearense, segundo o tamanho do estabelecimento - Ceará - 2006/2014

\begin{tabular}{cccccc}
\hline $\begin{array}{c}\text { Número de } \\
\text { trabalhadores por porte } \\
\text { da indústria }\end{array}$ & \multicolumn{2}{c}{$\mathbf{2 0 0 6}$} & \multicolumn{2}{c}{$\mathbf{2 0 1 4}$} & $\begin{array}{c}\text { Variação } \\
(\mathbf{\%})\end{array}$ \\
\hline Micro (1 a 19) & 11.074 & 21,05 & 14.215 & 20,26 & 28,36 \\
Pequena (20 a 99) & 16.578 & 31,52 & 18.767 & 26,74 & 13,20 \\
Média (100 a 499) & 9.032 & 17,17 & 17.006 & 24,23 & 88,29 \\
Grande (acima de 499) & 15.914 & 30,26 & 20.190 & 28,77 & 26,87 \\
Total & $\mathbf{5 2 . 5 9 8}$ & $\mathbf{1 0 0 , 0 0}$ & $\mathbf{7 0 . 1 7 8}$ & $\mathbf{1 0 0 , 0 0}$ & $\mathbf{3 3 , 4 2}$ \\
\hline
\end{tabular}

Fonte: Elaborado pelos autores a partir da RAIS/MTE.

Para Silva Filho e Queiroz (2010), esse cenário de crescimento de micro, pequenas e médias indústrias se realizam devido os estímulos e 
incentivos proporcionados pelo Governo Federal, através do Serviço Brasileiro de apoio às Micro e Pequenas Empresas (SEBRAE), que orienta, através de acompanhamento, os pequenos empresários, através de políticas de capacitação de novos empreendimentos, ou de formas diferenciadas de tributação (Simples Nacional ou Super Simples, por exemplo), que dispensam esses empreendedores de maiores obrigações tributárias. Sendo assim, novos empreendimentos são gerados, novos postos de trabalho são criados, e os benefícios facilitam a criação de pequenas e médias empresas e até micros empreendimentos familiares.

Assim, tal afirmação pode ser observada analisando o número de empregos formais gerados por tais portes da indústria. A micro indústria aumentou de 11.074 em 2006 para 14.215 trabalhadores em 2014. Quanto as pequenas indústrias aumentaram de 16.578 (2006) para 18.767 (2014) trabalhadores. As médias indústrias quase que duplicaram de 9.032 (2006) para 17.006 (2014), correspondendo a uma variação total de 88,29\%. Enquanto as indústrias de grande porte saltaram de 15.914 (2006) para 20.190 (2014) de mão de obra empregada na indústria têxtil.

\section{1) Perfil Sociodemográfico e Socioeconômico dos Empregados Formais na Indústria Têxtil Cearense}

No que concerne ao número de trabalhadores formas na indústria têxtil (Tabela 5), em 2006, havia 52.598 mil, sendo deste total 21.447 (40,83\%) do sexo masculino e, 31.121 ou 59,17\% do sexo feminino. Em 2014, houve um aumento de $33,42 \%$ (variação percentual total), aumento o número de trabalhadores para 70.178. Desse total, 27.736 (39,52\%) são do sexo masculino e $42.442(60,48 \%)$ correspondem ao sexo feminino, com destaque significativo para elas. Portanto, no intervalo compreendido pelos dois mandatos do governo Cid Gomes, em termos relativos, a inserção feminina na indústria cearense elevou-se.

Tabela 5: Número de trabalhadores formais na indústria têxtil cearense, segundo o sexo - 2006/2014

\begin{tabular}{cccccc}
\hline \multirow{2}{*}{ Sexo } & \multicolumn{2}{c}{$\mathbf{2 0 0 6}$} & \multicolumn{2}{c}{$\mathbf{2 0 1 4}$} & Variação \\
& Abs. & $(\boldsymbol{\%})$ & Abs. & $(\boldsymbol{\%})$ & $\mathbf{2 0 0 6 / 2 0 1 4}$ \\
\hline Masculino & 21.477 & 40,83 & 27.736 & 39,52 & 29,14 \\
Feminino & 31.121 & 59,17 & 42.442 & 60,48 & 36,38 \\
Total & $\mathbf{5 2 . 5 9 8}$ & $\mathbf{1 0 0 , 0 0}$ & $\mathbf{7 0 . 1 7 8}$ & $\mathbf{1 0 0 , 0 0}$ & $\mathbf{3 3 , 4 2}$ \\
\hline
\end{tabular}

Fonte: Elaborado pelos autores a partir da RAIS/MTE. 
Com relação a faixa etária, os dados da Tabela 6 mostram que os indivíduos com até 17 anos apresentam baixa inserção na indústria têxtil cearense, com participação de 0,47\% (248) em 2006, arrefecendo para 0,37\% (262) em 2014. Isso se dar, em parte, aos programas governamentais de incentivo a permanência de crianças e adolescentes na escola, como o Programa de Erradicação do Trabalho Infantil (PETI) e o Programa Bolsa Família (PBF) (GONÇALVES, 2006; ARRAIS, 2007; SILVA FILHO, 2008; QUEIROZ, REMY, PEREIRA, 2010).

Tabela 6: Número de trabalhadores formais na indústria têxtil cearense, segundo a faixa etária - 2006/2014

\begin{tabular}{cccccc}
\hline \multirow{2}{*}{ Faixa etária } & \multicolumn{2}{c}{$\mathbf{2 0 0 6}$} & \multicolumn{2}{c}{$\mathbf{2 0 1 4}$} & Variação (\%) \\
\cline { 2 - 5 } & Abs. & $\mathbf{( \% )}$ & Abs. & $\mathbf{( \% )}$ & $\mathbf{2 0 0 6 / 2 0 1 4}$ \\
\hline Até 17 anos & 248 & 0,47 & 262 & 0,37 & 5,65 \\
18 a 24 & 10.969 & 20,85 & 14.614 & 20,82 & 33,23 \\
25 a 29 & 11.132 & 21,16 & 14.203 & 20,24 & 27,59 \\
30 a 39 & 17.011 & 32,34 & 22.429 & 31,96 & 31,85 \\
40 a 49 & 10.179 & 19,35 & 12.826 & 18,28 & 26,00 \\
50 a 64 & 2.995 & 5,69 & 5.713 & 8,14 & 90,75 \\
65 ou mais & 64 & 0,12 & 130 & 0,19 & 103,13 \\
Ignorado & 0 & 0,00 & 1 & 0,00 & - \\
Total & $\mathbf{5 2 . 5 9 8}$ & $\mathbf{1 0 0 , 0 0}$ & $\mathbf{7 0 . 1 7 8}$ & $\mathbf{1 0 0 , 0 0}$ & $\mathbf{3 3 , 4 2}$ \\
\hline
\end{tabular}

Fonte: Elaborado pelos autores a partir da RAIS/MTE.

Por sua vez, os jovens de 18 a 24 anos representam 10.969 ou 20,85\% do total de ingresso em 2006, e aumenta para 14.614 pessoas, mas arrefece discretamente para 20,82\% em 2014. Nesse ensejo, o grupo de 25 a 29 anos segue a mesma tendência, aumentando o volume absoluto e, por outro lado, mostra arrefecimento percentual, ao sair de $11.132(21,16 \%)$ trabalhadores em 2006, para $14.203(20,24 \%)$ em 2014.

No que se refere ao grupo de 30 a 39 anos (idade ativa), esse concentra a maior parte dos empregados, com um volume de 17.011 mil $(32,34 \%) \mathrm{em}$ 2006, aumentando para 22.429 mil (31,96\%) em 2014. Ademais, faz-se importante ressaltar que houve aumento absoluto em todas as faixas de idades no interregno 2006/2014 (Tabela 6).

No tocante a população de 40 a 49 anos, essa teve uma absorção pelo mercado de trabalho um pouco menor (quando comparada a outras faixas), ao passar de 10.179 ou 19,35\% empregados em 2006 para 12.826 ou 18,28\% em 2014. Vale destacar que os indivíduos com idade de 50 a 64 anos, também 
exibem aumento nos anos em análises, com 2.995 (5,69\%) trabalhadores em 2006, passando para $5.713(8,14 \%)$ em 2014. Portanto, possivelmente, essa elevação decorre da maior demanda do mercado, que buscam ocupados com maior experiência e bastante vigor físico (DEDECA E CUNHA, 2004).

Quanto aos que possuem 65 anos ou mais, constata-se baixa participação absoluta com apenas 64 trabalhadores $(0,12 \%)$ em 2006, aumentando para $130(0,19 \%)$ em 2014. A explicação para o baixo volume de pessoas nessa idade, segundo Arrais (2007), é devido à falta de demanda por trabalhadores nessa faixa etária e também, pelo fato da maioria já estarem aposentados.

Considerando o nível de instrução dos trabalhadores (Tabela 7), uma quantidade expressiva possuía em 2006 Ensino Médio Incompleto em 2006, representando $43,10 \%$ dos trabalhadores inseridos na indústria têxtil. $O$ número para 2014 com este nível de ensino completo aumenta para $61,06 \%$ em 2014. Isso se deve as imposições do mercado, que cada vez mais demanda mão de obra qualificada.

Ademais, de acordo com Mota (2005), as políticas educacionais implantadas no estado Ceará nos últimos anos, de certa forma serviram de incentivos, pois se fixavam nos seguintes tópicos: mobilização e universalização do ensino na faixa etária obrigatória, que corresponde ao Ensino Fundamental (7 a 14 anos); permanência na escola (diminuição da evasão, repetência, reprovação e correção das distorções idade/série); financiamento e, por fim, gestão escolar, com destaque para os processos de descentralização e municipalização.

Tabela 7: Número de trabalhadores formais na indústria têxtil cearense, segundo o nível de instrução - 2006/2014

\begin{tabular}{cccccc}
\hline \multirow{2}{*}{ Nível de instrução } & \multicolumn{2}{c}{$\mathbf{2 0 0 6}$} & \multicolumn{2}{c}{$\mathbf{2 0 1 4}$} & Variação (\%) \\
\cline { 2 - 5 } & Abs. & $\mathbf{( \% )}$ & Abs. & $\mathbf{( \% )}$ & $\mathbf{2 0 0 6 / 2 0 1 4}$ \\
\hline Sem Inst. até Fund. Inc & 10.057 & 19,12 & 7.182 & 10,23 & $-28,59$ \\
Fund. Comp. até Méd. Inc. & 22.671 & 43,10 & 18.173 & 25,90 & $-19,84$ \\
Méd. Comp. até Sup. Inc & 19.027 & 36,17 & 42.853 & 61,06 & 125,22 \\
Superior Completo & 837 & 1,59 & 1.939 & 2,76 & 131,66 \\
Mestrado & 5 & 0,01 & 17 & 0,02 & 240,00 \\
Doutorado & 1 & 0,00 & 14 & 0,02 & $1.300,00$ \\
Total & $\mathbf{5 2 . 5 9 8}$ & $\mathbf{1 0 0 , 0 0}$ & $\mathbf{7 0 . 1 7 8}$ & $\mathbf{1 0 0 , 0 0}$ & $\mathbf{3 3 , 4 2}$ \\
\hline
\end{tabular}

Fonte: Elaborado pelos autores a partir da RAIS/MTE.

Os que possuem nível superior também se destacam, ao sair de 837 em 2006, para 1.939 em 2014. Isso é devido a chamada "era da globalização", 
onde o mercado seleciona mais, exige responsabilidade, qualidade e principalmente conhecimento. E os profissionais têm que estarem aptos as exigências do mercado que passa por transformações diariamente (TREVISAN, 2001).

No tocante aos trabalhadores sem nenhuma instrução até o ensino médio incompleto, os mesmos representaram 62,22\% em 2006 do total de indivíduos com atuação formal na indústria cearense, em 2014 esse número cai para 36,13\%. Para Chahad (1998), essa redução se deve as restrições do mercado quanto à absorção dessa força de trabalho desprovida de capital humano. Assim, a baixa escolaridade dos trabalhadores, sem sombra de dúvida, caracteriza o mercado de trabalho atual. Porém, o nível de instrução tem se tornado um requisito fundamental para inserção no segmento industrial, dado o avanço do progresso técnico.

Cabe destacar que dentre as indústrias que predominam no Ceará, a indústria têxtil tem se mostrado bastante ativa. E tanto esta como as outras (calçadista e alimentícia) exigem de seus candidatos a vagas de emprego uma baixa qualificação, onde "a função dos trabalhadores, em geral, é repetir movimentos padronizados, sem nenhum conhecimento técnico, feitos mecanicamente sem ajuda da mente" (ARRAIS, 2007, p. 61).

Com relação aos trabalhadores que possuem nível de instrução mais elevado, "Mestrado e Doutorado", em 2006, representaram apenas 6 (0,01\%) empregados na indústria têxtil, e aumenta para $31(0,04 \%)$ em 2014, com uma variação de $1.540 \%$ (Tabela 7). Esse resultado mostra que a indústria instalada no Ceará não demanda mão de obra qualificada, dado que o número percentual de quem possui mestrado e doutorado é praticamente "insignificante".

Quanto ao tempo de permanência dos trabalhadores na indústria formal (Tabela 8), observa-se que em 2006, 31,39\% passava de 1 a 3 anos no mesmo emprego, em 2014, eles migram para menos de 1 ano $(32,98 \%)$.

Com relação aos trabalhadores que passam menos de 5 anos no mesmo posto de trabalho, em 2006, a sua participação foi de 13,68\% (7.195), caindo para 14,26\% (10.007) em 2014. No que diz respeito àqueles que trabalham na indústria de 5 anos ou mais, apresentaram um arrefecimento relativo de 23,82\% (12.529) em 2006, para 20,86\% (14.640) em 2014.

Esse resultado pode estar associado, em parte, à substituição de trabalhadores experientes por aqueles mais jovens que, em geral, são remunerados com menores salários, o que é vantajoso para as indústrias. De acordo com Costa (1999, p. 535): 
A introdução do modelo japonês de organização do trabalho e da empresa exige a introdução de novas técnicas, métodos e de organização do trabalho e de gestão da produção. No Brasil esse processo ficou conhecido por terceirização, a qual tem promovido a elevação da precariedade nos contratos de trabalho, codificado a duração nas jornadas de trabalho, fazendo surgir novas formas de remunerar o trabalhador exigindo deste, também, mais habilidade, criatividade e qualificação [...]

Tabela 8: Número de trabalhadores formais na indústria têxtil cearense, segundo o tempo de emprego - 2006/2014

\begin{tabular}{cccccc}
\hline \multirow{2}{*}{ Tempo de emprego } & \multicolumn{2}{c}{$\mathbf{2 0 0 6}$} & \multicolumn{2}{c}{$\mathbf{2 0 1 4}$} & Variação (\%) \\
\cline { 2 - 5 } & Abs. & $\mathbf{( \% )}$ & Abs. & $(\boldsymbol{\%})$ & $\mathbf{2 0 0 6 / 2 0 1 4}$ \\
\cline { 2 - 4 } Menos de 1 ano & 16.366 & 31,12 & 23.147 & 32,98 & 41,43 \\
1 a menos de 3 anos & 16.508 & 31,39 & 22.384 & 31,90 & 35,59 \\
3 a menos de 5 anos & 7.195 & 13,68 & 10.007 & 14,26 & 39,08 \\
5 ou mais anos & 12.529 & 23,82 & 14.640 & 20,86 & 16,85 \\
Total & $\mathbf{5 2 . 5 9 8}$ & $\mathbf{1 0 0 , 0 0}$ & $\mathbf{7 0 . 1 7 8}$ & $\mathbf{1 0 0 , 0 0}$ & $\mathbf{3 3 , 4 2}$ \\
\hline
\end{tabular}

Fonte: Elaborado pelos autores a partir da RAIS/MTE.

No tocante ao rendimento dos trabalhadores formais inseridos na indústria têxtil do Ceará, observa-se através dos resultados da Tabela 9, maior concentração na faixa de 1 a 2 salários mínimos, sendo que em 2006 havia 38.950 ou $74,05 \%$ dos ocupados, passando para 53.186 ou $75,79 \%$ em 2014, mostrando crescimento em termos absolutos.

Esse resultado mostra que mesmo com todos os avanços, os trabalhadores ainda auferem uma remuneração baixa, o que evidencia uma falta de reconhecimento e desestímulo do trabalho. Além de aumentar a desestruturação dos mercados de trabalho regionais e incentivar o avanço das disparidades salariais e regionais (DIEESE, 2006).

Quanto aos que ganham até 1 salário mínimo, é possível notar aumento no grupo de trabalhadores, ao passar de 4.378 (8,32\%) em 2006 e se eleva para $6.633(9,45 \%)$ em 2014. Isso reflete o empobrecimento dessa classe em todo o estado. Tal fenômeno é justificado pela inserção de mão de obra desqualificada e barata, as quais são intensivas em atividades manuais. Ademais, o chamado "exército de reserva" está apto a assumir diferentes postos de empregos independentes do rendimento, o que explica e traz para si, a responsabilidade do crescimento de trabalhadores com essas condições de salários (SILVA FILHO, 2008). 
Tabela 9: Número de trabalhadores formais na indústria têxtil cearense, segundo o rendimento em salário mínimo - 2006/2014

\begin{tabular}{cccccc}
\hline \multirow{2}{*}{$\begin{array}{c}\text { Rendimento em salário } \\
\text { mínimo }\end{array}$} & \multicolumn{2}{c}{$\mathbf{2 0 0 6}$} & \multicolumn{2}{c}{$\mathbf{2 0 1 4}$} & Variação \\
\cline { 2 - 5 } & Abs. & $\mathbf{( \% )}$ & Abs. & $(\boldsymbol{\%})$ & $\begin{array}{c}\mathbf{\%}) \\
\mathbf{2 0 0 6 / 2 0 1 4}\end{array}$ \\
\hline Até 1 Salário & 4.378 & 8,32 & 6.633 & 9,45 & 51,51 \\
1 a 2 SM & 38.950 & 74,05 & 53.186 & 75,79 & 36,55 \\
2 a 3 SM & 5.546 & 10,54 & 4.931 & 7,03 & $-11,09$ \\
3 a 5 SM & 1.712 & 3,25 & 2.229 & 3,18 & 30,20 \\
5 a 10 SM & 850 & 1,62 & 1.139 & 1,62 & 34,00 \\
10 a 20 SM & 230 & 0,44 & 219 & 0,31 & $-4,78$ \\
Mais de 20 SM & 58 & 0,11 & 48 & 0,07 & $-17,24$ \\
Ignorado & 874 & 1,66 & 1.793 & 2,55 & 105,15 \\
Total & $\mathbf{5 2 5 9 8}$ & $\mathbf{1 0 0 , 0 0}$ & $\mathbf{7 0 1 7 8}$ & $\mathbf{1 0 0 , 0 0}$ & $\mathbf{3 3 , 4 2}$ \\
\hline
\end{tabular}

Fonte: Elaborado pelos autores a partir da RAIS/MTE.

E segundo Lima (1997), ainda persiste o pensamento que se a globalização está em busca de mão de obra barata, é melhor que essas oportunidades substanciais venham para o povo cearense. Levando em consideração que é melhor ganhar um salário mínimo a não receber nada.

Para os que auferem rendimentos entre 2 e 3 salários mínimos, essa classe de rendimento está em segunda posição com 5.546 (10,54\%) em 2006, diminuindo para 4.931 (7,03\%) em 2014. Quanto ao grupo de indivíduos que recebem entre 3 e 5 salários, apontam uma dinâmica um pouco diferenciada ao grupo anterior, ao aumentar de 1.712 ou 3,25\% em 2006, para 2.229 ou $3,18 \%$ em 2014. Conforme Baltar (1994), uma elevação salarial dos empregados se explica pelo nível de escolaridade, pois quanto maior este for, maior será o salário inicial.

Por sua vez, chama atenção para os trabalhadores que ganham acima de 5 salários mínimos, dado que é um número bastante inferior. Ao somar as últimas faixas de rendimentos, constata-se que em 2006 tinham em termos absolutos 2.012 trabalhadores, já em 2014 se eleva para 3.199, mas com diminuição na participação relativa de $3,83 \%$ para 4,55\%, respectivamente.

Nesse contexto, diante dessas análises, cabe destacar o aumento no número de estabelecimentos e portanto, trabalhadores formais no ramo têxtil de atividade no Ceará, o que é muito relevante, ao se deparar diariamente com tanta informalidade no estado. Sem dúvida, estar ligado aos incentivos do governo para o avanço industrial. Além disso, a indústria de transformação vem se mostrando bastante ativa e crescente no Ceará, dado o 
crescimento dos seus principais setores de atividade: têxtil, calçadista e alimentício.

Ademais, o número de trabalhadores vem aumentando substancialmente na indústria têxtil, o que contribui para o crescimento da mesma. Nota-se ainda, que este ramo de atividade industrial vem crescendo no mercado de trabalho cearense e, portanto, atraindo candidatos para ocupação de vagas, dado o desemprego que assusta cada vez mais e as oportunidades geradas neste setor de atividade.

\section{6) CONSIDERAÇÕES FINAIS}

O presente estudo teve como objetivo analisar as características das indústrias têxteis formais instaladas no Ceará, bem como traçar o perfil sociodemográfico e socioeconômico dos empregados em tal atividade, em 2006 e 2014, precisamente antes do primeiro mandato do governo Cid Gomes (2006) e ao término do seu segundo (2014), procurando verificar se houve avanços ou retrocessos no mercado de trabalho cearense.

Com relação às características da atividade econômica cearense, em termos gerais, os primeiros resultados revelam um aumento na quantidade de estabelecimentos no estado, com concentração em atividades comerciais, seguida pelos serviços, indústria e construção civil. Cabe destacar, o avanço na indústria e na construção civil, dado a construção de prédios públicos, programas de habitação, etc. implantados no Governo Cid Gomes.

No tocante ao número de estabelecimentos segundo grandes setores, a indústria têxtil (foco deste estudo) e de alimentos e bebidas se destacaram, avançando o número de estabelecimentos formais no interregno dos anos de 2006 e 2014.

Nesse contexto, no que concerne ao número de trabalhadores empregados no mercado de trabalho formal no setor têxtil cearense, entre 2006 e 2014, houve aumento na quantidade de empregos de 52.598 para 70.178 (com quedas e avanços ao longo do interregno estudado), o que é considerado um avanço significativo, mostrando que este setor vem contratando cada vez mais.

Quanto ao número de trabalhadores segundo o tamanho do estabelecimento, observou-se um avanço no número de indústrias do ramo têxtil atraídas e instaladas no Ceará gerando cada vez mais empregos, com destaque para as de pequeno e grande porte, evidenciando que o Fundo de Desenvolvimento Industrial (FDI) foi eficiente na atração de indústrias e 
criação de empregos, especialmente por atrair indústrias de transformação, intensivas em mão de obra, como a indústria têxtil, calçadista e alimentícia, que são as que mais se instalam no Ceará. Vale salientar, que o governo com seus incentivos, junto ao SEBRAE, obteve êxito na atração de indústrias e geração de empregos.

Quanto ao perfil sociodemográfico e socioeconômico dos empregados na indústria formal cearense, os dados revelam que estes são notadamente do sexo feminino, na faixa etária de 30 a 39 anos e permanecem por um ano a menos de três no mesmo emprego.

Considerando o nível de instrução dos trabalhadores, os resultados mostram que, no ano de 2006, a maioria possui o ensino fundamental completo até o médio incompleto, e em 2014, a maioria possui o ensino médio completo até superior incompleto, com uma substancial melhora relativa nos indicadores educacionais. Ademais, vale destacar o aumento de trabalhadores com o ensino superior completo. Mostrando, portanto, uma melhora na educação dos trabalhadores durante o governo Cid Gomes.

Faz-se importante salientar que apesar da diminuição de trabalhadores com baixa escolaridade, esse grupo supera o número de admitidos com nível de instrução mais elevado. Isso porque, os principais tipos de indústrias que predominam no Ceará, buscam trabalhadores com baixa qualificação (têxtil, calçadista e alimentícia), ao demandar mais a força manual e movimentos padronizados.

No que concerne ao rendimento/remuneração dos trabalhadores no setor têxtil de atividade, tanto no ano de 2006 e 2014, auferiam remuneração de 1 a 2 salários mínimos. O que ainda evidencia na indústria têxtil cearense, a existência/permanência de um dos princípios fundamentais do capitalismo: que por meio de indústrias intensivas em mão de obra, ainda gera-se a exploração do homem pelo homem.

Observa-se também, um avanço expressivo de estabelecimentos e de trabalhadores no setor têxtil de atividade, aliadas as políticas públicas de educação e de infraestrutura implementadas durante a gestão em questão. Condicionada as políticas de incentivos para a vinda de indústrias. Porém, o capital gerado por elas nem sempre se reverte no tão sonhado desenvolvimento.

Portanto, no Ceará, se evidencia não somente a necessidade de políticas de atração de indústrias, mas principalmente políticas públicas que venham a reduzir as disparidades sociais que se fazem ainda "assustadoras", priorizando assim, a valorização à educação como ferramenta de mobilidade 
social do trabalhador e os postos de trabalho com melhores rendimentos para se chegar à primeira.

Enfim, estudos posteriores poderão aprofundar-se mais quanto aos fatores ligados ao crescente avanço da indústria têxtil no Ceará, como também, a atração de trabalhadores para este setor de atividade, dado o número crescente dos mesmos. 


\section{REFERÊNCIAS}

ALMEIDA, C. S. O impacto das políticas industriais na economia cearense. Monografia (Bacharelado em Economia). FEAAC/UFC, 2001,62p.

ARAÚJO, N. G. A industrialização no Ceará: breves considerações. Boletim Goiano de Geografia, Goiás, v.27, n.2, jan/jun.2007. Disponível em: <http://www.redalyc.org/articulo.oa?id=337127147004>. Acesso em 27 de maio de 2016.

ARRAIS, A. K. M. Mercado de trabalho Formal Industrial: Comparativo entre as Regiões Sudeste e Nordeste nos anos de 1994 e 2004, Monografia (Graduação em Economia), Universidade Regional do Cariri (URCA), 2007.

BALTAR, P. E. A. Rotatividade de Mão-de-Obra e Diferenciação das Remunerações no Estado de São Paulo. Economia e Sociedade (UNICAMP), Campinas - SP, v. 3, 1994. Disponível em: <www.eco.unicamp.br/docprod/downarq.php?id=419\&tp=a>, acesso em: 19 de maio de 2016.

BARBOSA, D. F.; SANTOS, S. M.; SOARES, F. A.; SAMPAIO, A. M. B. O comportamento do primeiro emprego na indústria de transformação do estado do Ceará.Id on Line Revista de Psicologia, Julho de 2012, vol.1, n.17, p. 65-94. ISSN 1981-1189.

BEZERRA, E; BARBOSA, E. Desempenho Econômico do estado do Ceará em Anos Recentes, Texto para Discursão $\mathbf{N}^{\circ}$ 79, do Instituto de Pesquisa e Estratégia Econômica do Ceará (IPECE), $\quad$ Fortaleza, 2010. $\quad$ Disponível em:< http://www.ipece.ce.gov.br/publicacoes/textos_discussao/TD_79.pdf>, acesso em: 20 de maio de 2016.

BNB, 2010. Banco do Nordeste do Brasil. Páginas eletrônicas. Disponível em:

<http://www.bnb.gov.br>. Acesso em 05 de Abril de 2016.

CARVALHO, F. F. de. Da esperança à crise - A experiência das políticas regionais no Nordeste. Campinas, SP: UNICAMP - Instituto de Economia 2001. (Dissertação de Mestrado). 164p.

CARVALHO, O. Desenvolvimento regional.Rio de Janeiro: Campus, 1979.

CHAHAD, J. P. Z. Estabilização e desemprego em tempo de miudança: realidade e desafios no caso brasileiro,revista Indicadores Econômicos FEE, da Fundação de Economia e Estatística Siegfried Emanuel Heuser, v. 26, n. 2, 1998. Disponível em: < http://revistas.fee.tche.br/index.php/indicadores/article/view/1343/1710>, acesso em: 20 de maio de 2016.

CONFEDERAÇÃO NACIONAL DA INDÚSTRIA (CNI). Perfil da Indústria nos Estados 2014. - Brasília: CNI, 2014. 214 p. il. Disponível em: <http://www.fiemt.com.br/arquivos/1687_0511-perfildaindstrianosestados2014.pdf>. Acesso em: 23 de maio de 2016. 
COSTA, S. S. Emprego e qualificação: uma necessidade brasileira ante um processo de aberturara de mercados. In: II Encontro Regional da Associação Brasileira de Estudos do Trabalho. João Pessoa: ABET, 1999, v.2.

DEDECCA, C. Notas sobre a evolução do mercado de trabalho no Brasil. Revista de Economia Política,v.1, n.25, Jan- Março de 2005.

DIEESE 50 Anos (2006). Quem são os ocupados que ganham salário mínimo. Nota técnica Número 39 Novembro de 2006. Disponível em:< http://www.midiaindependente.org/media/2006/12/369480.pdf> Acesso em: 19 de maio de 2016.

DINIZ, C. C. Celso Furtado e o desenvolvimento regional.Nova econ. vol.19 no.2 Belo Horizonte May/Sept. 2009.Disponível em:

$<$ http://www.scielo.br/scielo.php?script=sci arttext\&pid=S0103-63512009000200001 $>$ Acesso em 28 maio de 2016.

DINIZ, C. C.A Industrialização Nordestina recente e suas perspectivas-Fortaleza: Banco do Nordeste do Brasil, 2004.

GONÇALVES, M. S. Desconcentração Industrial e seus Impactos Sobre o Mercado de Trabalho Formal na Indústria Cearense nos anos de 1994,1998 e 2002, Monografia (Graduação em Economia), Universidade Regional do Cariri (URCA), 2006.

IPECE, Anuário Estatístico do Ceará, Fortaleza, 2009.

IPECE- Instituto de Pesquisa e Estratégia Econômica do Ceará. Impactos Econômicos dos Principais Investimentos Públicos na Primeira Gestão do Governo Cid Gomes. ํo 29 . Ceará, Abril, 2012.

LIMA, Luiz Cruz. A industrialização recente do Ceará: uma introdução. In: Territorios en redefinicion, 1997, Buenos Aires. Lugar y Mundo en Latino Latina. Buenos Aires: Faculdad de Filosofia y Letras - UBA, 1997. v. único. p. 60-60.

LIMA JÚNIOR, F. O. Estrutura produtiva e rede urbana no Estado do Ceará durante o período de 1980-2010. Campinas, SP: [s.n], 2014.

MACEDO, F. C.; LIMA JÚNIOR, F. O.; MORAIS, J. M. L.; Dinâmica Econômica e Rede Urbana Cearense no Início do Século XXI. Santa Cruz do Sul, v. 17, n. 1, p. 70 - 93, jan/abr 2012.

MORAIS, J. M. L. Mudança institucional e desenvolvimento: uma abordagem institucional-evolucionária da política industrial do estado do Ceará. Rio de Janeiro: IEUFRJ (Tese de Doutorado), 2006.

MOTA, F. A. A política educacional no estado do ceará 1995-2002: reforma ou modernização conservadora? (1. Centro de Ciências Humanas, Universidade Estadual Vale do Acaraú - UVA). Anais da 57 Reunião Anual da SBPC - Fortaleza, CE - Julho/2005. 
Disponível

em:

http://www.sbpcnet.org.br/livro/57ra/programas/SENIOR/RESUMOS/resumo_440.html>.

Acesso em: 25 de Maio de 2016.

PONTES, P. A. VIANNA, P. J. R.; HOLANDA, M. C. A Política de Atração de Investimentos Industriais do Estado do Ceará: uma análise do período de 1995 a 2005. Fortaleza, Dezembro, 2006.

ROCHA, A. G. T. Velhos instrumentos, enfoque inovador: combinando subsídios fiscais e desenvolvimento local - o caso do Ceará. Anais do XXII Simpósio de Gestão da Inovação Tecnológica da NSP. Salvador - Bahia, 2002.

SILVA FILHO, L. A. A Trajetória da Indústria e do Emprego Formal no Ceará: 1996/2006, Monografia (Graduação em Economia), Universidade Regional do Cariri (URCA), 2008.

; QUEIROZ, Sa N. Industrialização e emprego formal no Ceará: análise a partir dos dados da RAIS/MTE - 1996/2006. Revista de desenvolvimento do Ceará - Ipece, $\mathrm{N}^{\circ}$ 01, Outubro, 2010.

QUEIROZ, S. N;. MOREIRA, I. T. Análise comparativa entre o perfil do migrante de retorno e o não natural do estado do Ceará. Revista Homem, Espaço e Tempo, v. 1, p. 2-17, ISSN 1982-3800, 2008.

QUEIROZ, S. N;. REMY, M. A. P. A.; PEREIRA, J. M. P. D. Estudo comparativo entre o Programa Bolsa Família no Brasil e o Programa Oportunidades no México. In: $13^{\circ}$ International Congress of the Basic Income Earth Network - BIEN, 2010, São Paulo. Anais do $13^{\circ}$ Intenational Congress of the Basic Income As An Instrument For Justice And Peace BIEN, 2010.

TREVISAN, A. M. As exigências e transformações do mercado de trabalho neste novo milênio. Guia Interativo de Informação Profissional e Educacional - GIIPE Centro de Integração Empresa-Escola - CIEE - Instituição não governamental e filantrópica. São Paulo, 2001. 